\title{
New concepts in intravenous fluid therapy
}

\section{Nuevos conceptos de la reanimación hídrica intravenosa}

\author{
Ángel A. Pérez-Calatayud ${ }^{1 *}$, Manuel A. Díaz-Carrillo², Eduardo D. Anica-Malagón ${ }^{3}$ and \\ Jesús C. Briones-Garduño ${ }^{4}$ \\ ${ }^{1}$ Adult Intensive Therapy Unit, Hospital de Especialidades del Niño y la Mujer Dr.Felipe Núñez Lara, Querétaro; ${ }^{2}$ Inhaloterapy Head Office, Hospital \\ Manuel Gea González, Mexico City; ${ }^{3}$ Department of Gynecological Intensive Therapy, Hospital General de México Eduardo Liceaga, Mexico City; \\ ${ }^{4}$ Obstetrics and Gynecology Department, Hospital General de México Eduardo Liceaga, Mexico City. Mexico
}

\begin{abstract}
Background: Intravenous fluid therapy is essential in the management of hospitalized patients, especially in those with acute or critical illness. It has been proposed four premises, four indications, four questions, and four phases for guidance of this fluid therapy. Objective: The objective of this manuscript is to review these new concepts of intravenous fluid therapy. Conclusion: These phases of intravenous fluid resuscitation coexist continuously and with a variability observed on fluid balance, is meant as a dynamic process, not as a temporary fixed pattern or a time scale and which must be individualized to the clinical context of patient.
\end{abstract}

KEY WORDS: Shock. Reanimation. Fluid balance. Critical illness.

\section{Resumen}

Antecedentes: La reanimación hídrica intravenosa es esencial en el manejo de los pacientes hospitalizados, en especial en aquellos con enfermedad aguda o crítica. En la actualidad se proponen cuatro premisas con cuatro indicaciones, cuatro preguntas y cuatro fases para la reanimación hídrica intravenosa. Objetivo: El objetivo de esta revisión es dar a conocer esta propuesta de manejo en la reanimación hídrica intravenosa. Conclusiones: Estas premisas de reanimación hídrica intravenosa coexisten de manera continua y con una variabilidad observada en el balance hídrico que se da a entender como un proceso dinámico, sin un patrón fijo temporal ni una escala de tiempo, el cual debe ser individualizado según el contexto clínico del paciente.

PALABRAS CLAVE: Choque. Reanimación hídrica. Balance hídrico. Enfermedad crítica.

\section{Background}

Intravenous fluid resuscitation is an essential therapy in the management of hospitalized patients, especially in those with acute illness or at critical state. While the correct use of this therapy is necessary to ensure survival of the patient in state of shock, current literature has shown that it is not free of risk. It is a fact that the use of certain solutions, the infused volume and organ failures related to disease itself cause an increase in morbidity and mortality.

In 2006, the SOAP ${ }^{1}$ study showed that it is a prognostic factor directly related to death in patients with sepsis. Subsequently, the VASST $^{2}$ study demonstrated an overwhelming survival decline in patients with sepsis secondary to the presence of a positive

\author{
Correspondence: \\ *Ángel A. Pérez-Calatayud \\ Av. Luis M. Vega Monroy, 1000 \\ Colinas del Cimatario \\ C.P. 76090, Santiago de Querétaro, \\ Qro., México \\ E-mail: gmemiinv@gmail.com
}

Date of reception: 20-04-2018

Date of acceptance: 06-05-2018

DOI: 10.24875/CIRUE.M18000052
Cir Cir. 2018;86:318-324

Contents available at PubMed www.cirugiaycirujanos.com 
balance during resuscitation and, at day 4 , with an increase of twice the risk of death.

Currently, an intravenous fluid resuscitation model has been proposed for patients with severe sepsis and has been adopted as the standard of care in the management of these patients in critical condition.

For every administered dose of a solution, toxicity depends on the type and composition of the administered fluid, on the physiology of the disease and on patient susceptibility. The debate regarding relative risk and benefit of the use of colloids and crystalloids has persisted for years, and currently the decision to resuscitate with a particular solution is made to a larger extent by individual preference and not based on existing evidence of quality clinical trials.

This review summarizes current concepts on fluid resuscitation, emphasizing individualization and risk reduction to improve patient evolution, by using action protocols for resuscitation.

\section{Conceptual framework for fluid resuscitation in the seriously ill patient}

In recent years, within the management of intravenous fluid resuscitation for the patient in critical condition, interrelated management phases have been proposed for intravascular volume and hemodynamics optimization, according to patient clinical status ${ }^{3}$.

The Acute Dialysis Quality Initiative XII (ADQI XII) research group proposes a conceptual management framework based on the risks related to fluid therapy, given that $20 \%$ of patients receive it inappropriately. The model proposes dealing with fluid therapy as with any drug, considering the pharmacokinetics, pharmacodynamics and toxicity, with the purpose to reduce the risk of complications ${ }^{4}$.

In a meta-analysis carried out by Malbrain et al. ${ }^{5}$, the use of a restrictive therapy, regardless of the type of solution employed, was shown to have a beneficial effect on mortality, intensive care unit days of stay and on the presence of abdominal hypertension.

This epidemiological model of fluid balance in the patient with acute kidney injury in critical condition can spread throughout the spectrum of critical disease ${ }^{6,7}$.

Currently, four premises are proposed, with four initiatives each.

\section{First premise: the $4 \mathrm{Ds}$}

It consists of the use of antibiotics' 4 Ds, and thus fluid therapy should start considering:
1. Drug: the type of solution to be infused. In this field, there is still great debate about which the best solution would be according to the patient scenario. Table 1 summarizes some of the current conclusions according to existing evidence.

2. Dosing: how much solution do we have to infuse? This will depend on the patient clinical scenario.

3. Duration: for how long should the patient be infused.

4. De-escalation: when to interrupt the infused volume

These premises are directly related to the resuscitation phases' proposal ${ }^{5}$ (fourth premise).

\section{Second premise: the four indications for intravenous fluid therapy}

Currently, intravenous fluid therapy is known to be essential in the management of hospitalized patients, mainly with four indications: resuscitation, maintenance, replacement and nutrition.

\section{Third premise: the four questions of fluid therapy}

Once starting fluid therapy is decided, we must always make the following four questions:

1. When to start fluid therapy?

There are numerous triggers that make a doctor start intravenous fluids administration. Traditionally, the way to assess intravascular volume is using macrocirculatory parameters, such as the presence of hypotension, tachycardia, etc., or by means of parameters associated with peripheral circulation perfusion, such as capillary refill time, central-ankle temperature gradient or skin mottling $^{9-11}$. In addition, clinicians observe the perfusion alteration in relation to organ function, such as the presence of acute cognitive dysfunction, oliguria and tachypnea. However, all these clinical parameters lack specificity and can have alternative causes, not related to hypoperfusion due to hypovolemia. Biomarkers such as lactate, an anaerobic metabolism marker, have been managed as a resuscitation goal, but they have also been a cause of controversy, since the stimulation effect of the Na-K-ATPase pump by epinephrine in hyperadrenergic states such as sepsis, trauma or different states of shock, is not always observed. Blood concentration, manifested by hematocrit or by protein concentration has 
Table 1. Current considerations in the use of intravenous solutions

- Isotonic or balanced solutions should be used for first-line resuscitation.

- Consider isotonic saline in case of hypovolemia or in patients with alkalosis.

- Use blood products in patients with active hemorrhage.

- Consider using colloids in patients with severe hypovolemia as second line.

- Use crystalloids in prehospital stabilization.

- Use blood products in patients with perioperative hemorrhage and in trauma patients.

- All solutions can cause interstitial edema.

- Albumin has shown benefit in the management of patients with sepsis and septic shock.

- Albumin is contraindicated in patients with traumatic brain injury.

- Consider the safety of other colloids in traumatic brain injury.

- Buffer solutions are recommended in major surgery patients and in burned patients.

- Saline is the solution of choice in patients with traumatic brain injury.

- The safety of synthetic colloids has not been demonstrated in any patient population.

- Starches are contraindicated in patients with sepsis.

- Starches are contraindicated in patients at risk of acute kidney failure.

- The safety of hypertonic saline solutions has not been established in any patient population.

- Saline should not be used in patients with metabolic acidosis (risk of hyperchloremic acidosis).

also been considered an indication to start intravenous fluid resuscitation in patients at critical areas. Of the static parameters, currently only central venous saturation is used in clinical practice guidelines for resuscitation. Finally, dynamic parameters, which are recommended to guide hemodynamic optimization of the seriously ill patient, are mainly based on the idea of cardiac function and on Starling curve as a hypoperfusion premise ${ }^{8}$.

2. When to stop intravenous fluid therapy? Although fluid overload is associated with poor evolution, in current literature there are no specific markers for stopping fluid administration. Expert recommendation focuses only on avoiding fluid overload. However, fluid administration should not be interrupted prematurely ${ }^{12}$. Different clinical and experimental variables are found in the literature. Signs of fluid overload, such as peripheral and pulmonary edema, are clear markers of this situation, and can also indicate poor fluid distribution in the absence of overt fluid overload, but these signs, together with weight gain, are late markers and cannot be used in the perioperative period or in intensive care units. Among the laboratory tests, lactate clearance to guide intravenous fluid therapy in states of shock, as well as normalization of this parameter, might be used as markers to stop intravenous fluid therapy ${ }^{13}$. Among the static parameters, the increase in filling pressures, such as pulmonary artery wedge pressure or central venous pressure are (not for response to volume, but to give us an idea of tolerance to volume administration), could mark a limit to resuscitation. Finally, dynamic parameters ${ }^{14}$, which in general lack a significant increase after the leg elevation test or a challenge with fluids, are sensitive and specific indicators for not continuing with fluid administration. Extravascular lung water has been assessed for the quantification of acute pulmonary edema and edema formation ${ }^{15,16}$.

3. When to start de-resuscitation? Despite the evidence, currently there are no clinical or laboratory markers for de-resuscitation to be started in critically ill patients. However, by expert consensus, the following recommendations are established. Fluid overload avoidance intervention protocols should be resorted to, which means using dynamic parameters, early vasopressors in state of shock and evaluation of the response to volume. This is of vital importance in patients with sepsis, intra-abdominal hypertension and acute respiratory 
distress syndrome. After the resuscitation phase (fourth premise), it is recommended for balance to be neutral or negative from day 3 through 7 ; this includes the use of diuretics in patients with preserved kidney function or use of ultrafiltration by means of renal replacement therapy (low evidence) $)^{8}$. To the question on why starting de-resuscitation the only answer is that fluid overload is a cause for increased morbidity and mortality in seriously ill patients ${ }^{8}$.

4. When to stop de-resuscitation?

There is not enough evidence on this issue as to make a recommendation, but it should be assumed that active de-resuscitation might cause hypoperfusion and more harm to the patient. A neutral or slightly negative balance should be maintained, and available monitoring tools should be used ${ }^{8}$.

\section{Fourth premise: the four phases of intravenous fluid resuscitation}

The four phases for intravenous fluid resuscitation of patients in state of shock are: an initial or rescue phase whose priority is establishing measures to restore tissue perfusion and intravascular volume; an optimization phase to maintain intravascular volume restored; a stabilization phase to prevent end-organs damage after hemodynamic stabilization; and a de-resuscitation phase where the support is removed and the intrinsic hemodynamic function is restored (Fig. 1)

\section{RESCUE PHASE ${ }^{4}$}

During this phase, between hours 0 and 24, when there is symptomatic hypovolemia, most part of the solutions is administered. This phase anticipates and immediately escalates fluid therapy for resuscitation of the patient with severe shock (characterized by hypotension, hypoperfusion, or both), and is characterized by the use of liquid or intravenous solution bolus challenge ${ }^{4}$ (Table 2 ).

During this phase, the use of crystalloids is preferred as first-line management, with the exception of blood products when needed. Albumin might have a place at this resuscitation stage in patients with sep$\operatorname{sis}^{6,17,18}$; its use is contraindicated in case of traumatic brain injury ${ }^{19}$.

A fluid challenge is recommended at a dose of 20-30 mL/kg, mainly as a treatment for hypovolemia.

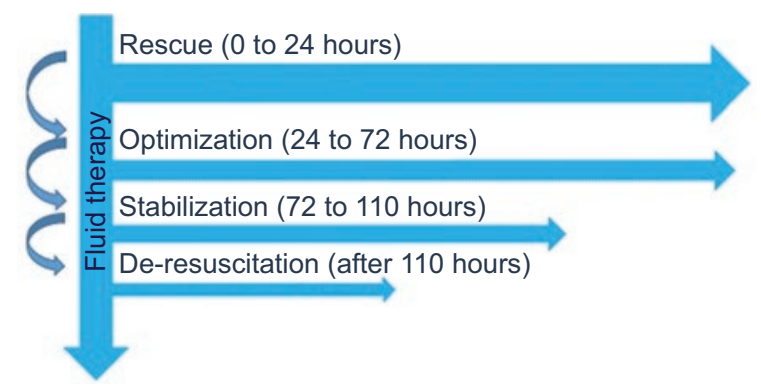

Figure 1. Administered volume behavior at the different resuscitation phases.

Evidence supporting the use of this therapy is limited and mainly based on consensus recommendations and clinical practice guidelines ${ }^{20}$. Currently, there are emerging data suggesting that lower doses yield the desired hemodynamic effect ${ }^{21}$.

The effectiveness and safety of resuscitation with crystalloid bolus is controversial. The FEAST study ${ }^{22}$, performed in pediatric population and in a center with limited resources, reported a 48-hour mortality increase in the bolus resuscitation group (Relative Risk [RR]: 1.45; 95\% Confidence Interval [Cl]: 1.13-1.86; $p=0.003$ ), and the authors concluded that the main cause was cardiovascular collapse and not volume overload or neurological factors, suggesting that an adverse interaction between intravenous solutions administration and the compensatory autonomic response may exist.

Early use of vasopressors, such as norepinephrine, is recommended as adjunctive therapy during resuscitation to reduce the volume that needs to be infused and improve tissue perfusion by increasing venous return, mean blood pressure and heart output.

\section{OPTIMIZATION PHASE ${ }^{5,8}$}

In this phase, at between 24 and 72 hours, the hypovolemia index has been significantly reduced, and smaller volumes are therefore needed for resuscitation $(5$ and $15 \mathrm{~mL} / \mathrm{kg}$ ). During this phase, the patient is in no imminent danger of death; he/she is in a compensated phase of the state of shock (at risk of decompensation) and administration of solutions should be carried out judiciously in order to optimize cardiac output, improve tissue perfusion and, as the main goal, to mitigate organ dysfunction ${ }^{5}$. In this phase, fluid challenge is used to observe patient hemodynamic response to intravascular volume administration and thus avoid fluid overload.

There is not enough scientific evidence showing that this therapeutic maneuver improves mean blood 
Cirugía y Cirujanos. 2018;86

Table 2. Characteristics of intravenous fluid resuscitation different phases

\begin{tabular}{|c|c|c|c|c|}
\hline Characteristic & Rescue & Optimization & Stabilization & De-resuscitation \\
\hline Main goals & $\begin{array}{l}\text { Life support } \\
\text { Correct state of shock }\end{array}$ & $\begin{array}{l}\text { Organ rescue } \\
\text { Optimize } \\
\text { and rescue tissue perfusion }\end{array}$ & $\begin{array}{l}\text { Organ rescue } \\
\text { Achieve negative or } \\
\text { neutral fluid balance }\end{array}$ & $\begin{array}{l}\text { Organ recovery } \\
\text { Mobilize accumulated } \\
\text { fluid }\end{array}$ \\
\hline Time (usual) & Minutes & Hours & Days & Days to weeks \\
\hline Phenotype & Severe shock & Instable & Stable & Recovery \\
\hline Fluid resuscitation & Bolus or quick loads & $\begin{array}{l}\text { Conservative fluid infusion and use } \\
\text { of challenge with fluids }\end{array}$ & $\begin{array}{l}\text { Minimum infusion } \\
\text { volume to } \\
\text { maintain adequate } \\
\text { balance } \\
\text { with losses }\end{array}$ & $\begin{array}{l}\text { Mobilization of fluids } \\
\text { to negative balance } \\
\text { and start oral route if } \\
\text { possible }\end{array}$ \\
\hline Clinical scenario & $\begin{array}{l}\text { Septic shock } \\
\text { Major trauma }\end{array}$ & $\begin{array}{l}\text { Burns, diabetic } \\
\text { ketoacidosis } \\
\text { Intraoperative goal-directed therapy }\end{array}$ & $\begin{array}{l}\text { Management in } \\
\text { acute pancreatitis }\end{array}$ & $\begin{array}{l}\text { Acute illness recovery } \\
\text { phase, on full enteral } \\
\text { nutrition } \\
\text { Kidney attack recovery }\end{array}$ \\
\hline
\end{tabular}

pressure, systemic perfusion or organ failure recovery, as observed in patients with acute kidney failure ${ }^{23}$. Most administered fluids, especially crystalloids, accumulate in the interstitial tissue under conditions of increased tissue permeability due to capillary leakage. The net effect of unnecessary and ineffective volume administration does not optimize systemic hemodynamic function, and increases accumulated balance with the ensuing formation of iatrogenic interstitial edema and an increase in mortality, in days on mechanical ventilation and on the need for renal replacement therapy, especially in patients with sepsis ${ }^{11}$ and acute respiratory distress syndrome ${ }^{24}$.

\section{STABILIZATION PHASE ${ }^{5}$}

This phase occurs during the $72^{\text {nd }}$ to the $96^{\text {th }}$ hour and reflects the point at which the patient is stable. It is distinguished from the first two phases by the absence of shock (compensated or decompensated), and fluid therapy at this phase is only for maintenance. At this phase, neutral or negative cumulative fluid balance must be achieved (Fig. 1).

Currently, there is scarce evidence on the effect of restrictive resuscitation strategies minimizing cumulative fluid balance ${ }^{25}$.

\section{DE-RESUSCITATION PHASE ${ }^{5,8}$}

The de-resuscitation or de-escalation phase, which usually occurs at 96 hours of management or when hemodynamic stability is achieved, has the purpose to attain a negative fluid balance by restricting intravenous fluids administration or by removing fluids with spontaneous diuresis induction or with diuretics.

A strategy for eliminating excessive fluid accumulated in the previous phases appears to be more intuitive; however, a strategy based on restricting excessive and unnecessary use might be effective ${ }^{26}$. There is no sufficient evidence on the use of hemofiltration to achieve this goal in the absence of acute renal failure ${ }^{23}$.

Interstitial edema adverse effects may not be prevented by simply removing fluid excess, especially in the administration of solutions with dose-dependent toxicity, such as starches. The strategy of restrictive use of fluids is associated with a poor neuropsychological prognosis in patients with acute respiratory distress syndrome ${ }^{27}$.

\section{Fluid toxicity}

Water accumulation is associated with increased morbidity and mortality, and especially with the development of acute renal failure ${ }^{28}$.

In patients with sepsis-associated acute renal failure, the use of intravenous solutions at a continuous volume does not increase the recovery of renal function and is associated with pulmonary function deterioration with oxygenation alterations ${ }^{29}$. Observational studies in critically ill patients show that the presence of acute renal failure associated with sepsis is a predictor of 60-day mortality (RR: 1.21/L for $24 \mathrm{~h}$; $95 \%$ $\mathrm{Cl}: 1.13-1.28 ; p<0.001)^{30}$. Furthermore, although the FACCT study did not show mortality differences between conservative vs. liberal fluid resuscitation in 
patients with acute lung injury, conservative therapy showed a trend towards a decrease in days of hospital stay, less need for renal replacement therapy and better pulmonary function ${ }^{25}$

The increase in fluid accumulation in both adult and pediatric patients with acute renal failure at the start of renal replacement therapy, is associated with an increase in mortality and decreases the probability of renal function recovery. For each $1 \%$ increase in volume overload at the start of renal replacement therapy there is a $3 \%$ increase in the risk of death ${ }^{31-35}$.

Failure to appreciate the fluid resuscitation phases can underestimate the phenomenon called "fluid creep", first identified in burned patients, in response to the enthusiasm for aggressive and sustained resuscitation $^{36}$. These observations underscore the importance of fluid balance monitoring in the critically ill patient, in particular after the rescue phase, when the input (e.g., medications, blood products, etc.) can exceed the output (e.g. oliguria, kidney attack) and lead to fluid overload ${ }^{37}$.

\section{Conclusions}

Numerous studies in critically ill and surgical patients have demonstrated the poor evolution of patients with fluid overload and its impact on morbidity and mortality. The intravenous fluid resuscitation phases continuously coexist. The variability observed in fluid balance is understood as a dynamic process, without a fixed temporal pattern or a timeline, and should be individualized according to the patient's clinical context. Fluid therapy inappropriate management, regardless of the type of solution or fluid used, can harm compensatory mechanisms. Although these concepts are currently used as an action protocol in fluid resuscitation of the critically ill patient, studies are still needed to validate them both in their clinical application and in basic research ${ }^{25}$.

\section{Conflicts of interest}

All the authors declare not having any conflicts of interest.

\section{References}

1. Vincent JL, Sakr Y, Sprung CL, Ranieri VM, Reinhart K, Gerlach H, et al. Sepsis in European intensive care units: results of the SOAP study. Sepsis Occurrence in Acutely III Patients Investigators. Crit Care Med. 2006:34:344-53

2. Boyd JH, Forbes J, Nakada T, Walley KR, Russell JA. Fluid resuscitation in septic shock: a positive fluid balance and elevated central venous pressure are associated with increased mortality. Crit Care Med. 2011; 39:259.

3. Goldstein SL. Fluid management in acute kidney injury. J Intensive Care Med. 2014;29:183-9.

4. Hoste EA, Maitland K, Brudney CS, Mehta R, Vincent JL, Yates D, et al. ADQI XII Investigators Group. Four phases of intravenous fluid therapy: a conceptual model. Br J Anaesth. 2014;113:740-7.

5. Malbrain MLNG, Marik PE, Witters I, Cordemans C, Kirkpatrick AW, Roberts DJ, et al. Fluid overload, de-resuscitation, and outcomes in critically ill or injured patients: a systematic review with suggestions for clinical practice. Anaesthesiol Intensive Ther. 2014;46:361-80.

6. Finfer S, Liu B, Taylor C, Bellomo R, Billot L, Cook D, et al.Resuscitation fluid use in critically ill adults: an international cross-sectional study in 391 intensive care units. Crit Care. 2010;14:R18.

7. McDermid RC, Raghunathan K, Romanovsky A, Shaw AD, Bagshaw SM. Controversies in fluid therapy: type, dose and toxicity. World J Crit Care Med. 2014;3:24-33.

8. Veenstra G, Ince C, Boerma EC. Direct markers of organ perfusion to guide fluid therapy: when to start, when to stop. Best Pract Res Clin Anaesthesiol. 2014;28:217-26.

9. Lima A, Jansen TC, van Bommel J, Ince C, Bakker J. The prognostic value of the subjective assessment of peripheral perfusion in critically ill patients. Crit Care Med. 2009;37:934-8.

10. Joly HR, Weil MH. Temperature of the great toe as an indication of the severity of shock. Circulation. 1969;39:131e8.

11. Ait-Oufella H, Lemoinne S, Boelle PY, Galbois A, Baudel JL, Lemant J, et al. Mottling score predicts survival in septic shock. Intensive Care Med. 2011;37(5): 801-7.

12. Ricci Z, Ronco C. Year in review 2012: critical care e nephrology. Crit Care. 2013;17:246.

13. Jansen TC, van Bommel J, Schoonderbeek FJ, Sleeswijk Visser SJ, van der Klooster JM, Lima AP, et al. Early lactate-guided therapy in intensive care unit patients: a multicenter, open-label, randomized controlled trial. Am J Respir Crit Care Med. 2010;182:752-61.

14. Trof RJ, Danad I, Reilingh MWL, Breukers RM, Groeneveld AB. Cardiac filling volumes versus pressures for predicting fluid responsiveness after cardiovascular surgery: the role of systolic cardiac function. Crit Care. 2011;15:R73

15. Jansen JRC, Maas JJ, Pinsky MR. Bedside assessment of mean systemic filling pressure. Curr Opin Crit Care. 2010;16:231-6.

16. Michard F. Bedside assessment of extravascular lung water by dilution methods: temptations and pitfalls. Crit Care Med. 2007;35:1186-92.

17. Finfer S, McEvoy S, Bellomo R, McArthur C, Myburgh J, Norton R. Impact of albumin compared to saline on organ function and mortality of patients with severe sepsis. Intensive Care Med. 2011;37:86-96.

18. Caironi $P$, Tognoni $G$, Masson $S$, Fumagalli $R$, Pesenti $A$, Romero $M$, et al. Albumin replacement in patients with severe sepsis or septic shock. N Engl J Med. 2014;370:1412-21.

19. Cooper DJ, Myburgh J, Heritier S, Finfer S, Bellomo R, Billot L, et al. Albumin resuscitation for traumatic brain injury: is intracranial hypertension the cause of increased mortality? J Neurotrauma. 2013; 30:512-8.

20. Dellinger RP, Levy MM, Rhodes A, Annane D, Gerlach H, Opal SM, et al. Surviving sepsis campaign: international guidelines for management of severe sepsis and septic shock, 2012. Intensive Care Med. 2013;39: 165-228.

21. Yealy DM, Kellum JA, Huang DT, Barnato AE, Weissfeld LA, et al. ProCESS Investigators. A randomized trial of protocol-based care for early septic shock. N Engl J Med. 2014;370:1683-93.

22. Maitland K, Kiguli S, Opoka RO, Engoru C, Olupot-Olupot P, Akech SO, et al. Mortality after fluid bolus in African children with shock. N Engl J Med. 2011;364:2483-95.

23. Prowle JR, Bellomo R. Fluid administration and the kidney. Curr Opin Crit Care. 2010;16:332-6.

24. Boyd JH, Forbes J, Nakada TA, Walley KR, Russell JA. Fluid resuscitation in septic shock: a positive fluid balance and elevated central venous pressure are associated with increased mortality. Crit Care Med. 2011; 39:259-65.

25. Wiedemann HP, Wheeler AP, Bernard GR, Thompson BT, Hayden D, deBoisblanc $B$, et al. Comparison of two fluid-management strategies in acute lung injury. N Engl J Med. 2006;354:2564-75.

26. Myburgh JA. Fluid resuscitation in acute medicine: what is the current situation? J Intern Med. 2015;277:58-68.

27. Mikkelsen ME, Christie JD, Lanken PN, Biester RC, Thompson BT, Bellamy SL, et al. The adult respiratory distress syndrome cognitive outcomes study: long-term neuropsychological function in survivors of acute lung injury. Am J Respir Crit Care Med. 2012;185:1307-15.

28. Finfer S, Bellomo R, Boyce N, French J, Myburgh J, Norton R. A comparison of albumin and saline for fluid resuscitation in the intensive care unit. N Engl J Med. 2004;350:2247-56.

29. Arikan AA, Zappitelli M, Goldstein SL, Naipaul A, Jefferson LS, Loftis LL. Fluid overload is associated with impaired oxygenation and morbidity in critically ill children. Pediatr Crit Care Med. 2012;13:253-8. 
30. Bellomo R, Cass A, Cole L, Finfer S, Gallagher M, Lee J, et al. An observational study fluid balance and patient outcomes in the Randomized Evaluation of Normal vs. Augmented Level of Replacement Therapy trial. Crit Care Med. 2012;40:1753-60.

31. Brunkhorst FM, Engel C, Bloos F, Meier-Hellmann A, Ragaller M, Weiler N, et al. Intensive insulin therapy and pentastarch resuscitation in severe sepsis. N Engl J Med. 2008;358:125-39.

32. Raghunathan K, Shaw A. Hydroxyethyl starch or saline in intensive care. N Engl J Med. 2013:368:774-5.

33. U.S. Food and Drug Administration. Silver Spring, 2013 Hydroxyethy Starch Solutions: FDA Safety Communication - Boxed Warning on Increased Mortality and Severe Renal Injury and Risk of Bleeding. (Consultado el 1 de febrero de 2016.) Disponible en: http://www.fda.gov/ Safety/MedWatch/SafetyInformation/SafetyAlertsforHumanMedicalProducts/ucm358349.htm.
34. Meybohm P, Van Aken H, De Gasperi A, De Hert S, Della Rocca G, Girbes $A R$, et al. Re-evaluating currently available data and suggestions for planning randomised controlled studies regarding the use of hydroxyethyl-starch in critically ill patients a multidisciplinary statement. Crit Care. 2013;17:R166.

35. Sutherland SM, Zappitelli M, Alexander SR, Chua AN, Brophy PD, Bunchman TE, et al. Fluid overload and mortality in children receiving continuous renal replacement therapy: the prospective pediatric continuous renal replacement therapy registry. Am J Kidney Dis. 2010;55:316-25.

36. Saffle JI. The phenomenon of "fluid creep" in acute burn resuscitation. J Burn Care Res. 2007;28:382-95.

37. Bagshaw SM, Brophy PD, Cruz D, Ronco C. Fluid balance as a biomarker: impact of fluid overload on outcome in critically ill patients with acute kidney injury. Crit Care. 2008;12:169. 